Letter

\title{
Medical Decision and Patient's Preference: 'Much Ethics' and More Trust Always Needed
}

\author{
Dimitrios Anyfantakis $^{1 凶}{ }^{\bowtie}$, Emmanouil K Symvoulakis $^{2}$ \\ 1. Primary Health Care Center of Kissamos, Chania, Crete, Greece \\ 2. Blood Donation Department, University General Hospital of Heraklion, Crete, Greece
}

$\triangle$ Corresponding author: Dimitrios Anyfantakis, MD, MSc in Bioethics, Primary Health Care Center of Kissamos, Chania, Crete, Greece. E-mail: danyfantakis@med.uoc.gr; Tel: 00306937473215 ; Fax: 00302822022532

(c) Ivyspring International Publisher. This is an open-access article distributed under the terms of the Creative Commons License (http://creativecommons.org/ licenses/by-nc-nd/3.0/). Reproduction is permitted for personal, noncommercial use, provided that the article is in whole, unmodified, and properly cited.

Received: 2011.04.02; Accepted: 2011.05.25; Published: 2011.05.31

\begin{abstract}
There is much discussion on medical ethics literature regarding the importance of the patients' right for self-determination. We discuss some of the limitations of patient's autonomy with the aim to draw attention to the ethical complexity of medical decision making in the everyday clinical practice.
\end{abstract}

Key words: autonomy, informed consent, medical decision making

There is much discussion on medical ethics literature regarding the importance of the patients' right for self-determination [1]. In practice, this means that after a thorough recognition of possible risks and benefits within the suggested therapeutic option, the patient makes his own free decision. However, stepping between physician's obligation for optimal care and patient's preferences, ethical difficulties are often raised [2]. Remarkably, in a survey of physicians' attitudes about life-sustaining interventions, although respect for patient autonomy was highly valued by the physicians, their actions were not always resulted cohesive to this principle [3]. In this brief communication, we discuss some of the limitations of patient's autonomy with the aim to draw attention to the ethical complexity of medical decision making in the everyday clinical practice.

Competence, clarity of the information provided by the physician and humanistic voluntariness are considered to be basic ingredients of a successful decision making process [4]. However, things are not always so simple. Cassileth et al. reported that 6 out of
10 patients did not understand the goal of their treatment [5]. Additional parameters that may constrain patient's autonomy include cost of therapy, limited public resources and difficult access to the place where therapy is provided [4]. Furthermore, alcohol addiction or psychiatric disorders also represent complex conditions that may interfere with the patient's decision making capacity [4].

In the acute hospital care, physicians offer their services at one point in time and orientate their duty of care towards the facilitation of immediate therapeutic results, frequently obtaining a conventional informed consent about acute therapeutic interventions [6]. The emotional stress of a patient suffering an urgent condition and the fact that his mental status is likely to be yet unassessed, often make physicians practically unable to decide on patient's decision making competency, especially in cases of treatment refusal [7]. This fact creates a gap between theory and practice without excluding cases of 'iatrogenic' paternalism [7]. 
Similar problems become even more challenging in the context of an Intensive Care Setting (ICU). The 'ephemeral' and acute case-contact in an ICU environment may compromise physicians' capacity to discuss end of life choices leading to further poor-skilled interactions of critical care staff with families [8]. Aspects of such limitations may become more evident when ICU specialized staff faces the refusal of a patient's family to consent to organ donation $[9,10]$. Not surprisingly, duration of the consent discussion and convincing response to families' concerns are related to higher donation consent rates [9].

From this standpoint, we feel the need to highlight the role of physicians, from primary to tertiary care, who maintain increasingly trustful relationships with their patients by offering compassion and humanity [11]. Understanding the ways that physical or psychological factors trigger patients' thinking, it is more likely to prevent damaging behaviors. By assessing patients' needs, physicians can support the integrity of patients' decision making process and enhance their autonomy with respect to their own and real preferences. In this direction, a multilevel assessment of the patients' needs is important in order to build efficient communication interventions. Rarely, one's decision for a less optimal care may be influenced by the manner that choices are given, particularly in systems that face conditions of crisis. In order to avoid this potential risk, efforts to install a universally accepted process of 'negotiation' based on concrete ethic values and do how deserve emphasis from the early undergraduate training of the care providers.

\section{Conflict of Interests}

We declare that we have no conflict of interests.

\section{References}

1. Rogers WA. Whose autonomy? Which choice? A study of GPs' attitudes towards patient autonomy in the management of low back pain. Fam Pract. 2002; 19: 140-5.

2. Lantos J, Matlock AM, Wendler D. Clinician Integrity and Limits to Patient Autonomy. JAMA. 2011; 305: 495-99.

3. Fried TR, Stein MD, O'Sullivan PS, Brock DW, Novack DH. Limits of patient autonomy. Physician attitudes and practices regarding life-sustaining treatments and euthanasia. Arch Intern Med. 1993; 153:722-8.

4. Rogers WA, Braunack-Mayer A. Making decisions: patient autonomy in general practice. In: Practical Ethics for General Practice. ed. Rogers WA, Braunack-Mayer A. Oxford: Oxford University Press; 2004: 101-24.

5. Cassileth BR, Zupkis RV, Sutton-Smith K, March V. Informed consent -- why are its goals imperfectly realized? N Engl J Med. 1980; 302: 896-900.

6 Doyal L. Ethico-legal dillemmas within general practice: moral indeterminacy and abstract morality. In: General Practice and Ethics. ed. C. Dowrick and L.Frith. London: Routledge; 1999: 45-61.
7. Ladd RE. Patients without choices: the ethics of decision-making in emergency medicine. J Emerg Med. 1985;3:149-56.

8. Smith SD, Nicol KM, Devereux J, Cornbleet MA Encounters with doctors: quantity and quality. Palliat Med. 1999; 13:217-23.

9. Siminoff LA, Gordon N, Hewlett J, Arnold RM. Factors influencing families' consent for donation of solid organs for transplantation. JAMA. 2001; 286:71-7.

10. Symvoulakis EK, Stavroulaki E, Morgan M, Jones R. Kidney organ donation: developing family practice initiatives to reverse inertia. BMC Health Serv Res. 2010; 10:127.

11. Shea S, Lionis C. Restoring humanity in health care through the art of compassion: an issue for teaching and research agenda in rural health care. Rural Remote Health. 2010; 10:1679. 